\title{
Mitigating Partisan Perceptions between Individual and Collective-based Groups*
}

\author{
JASPER S. KIM**
}

In our increasingly globalized and cross-border world, negotiators come across increasingly different cultures, and thus, methods of approaching solutions and problems. Often such cultures may seem "alien" or "unusual" to us, which may in turn give rise to certain partisan perceptions. Within the context of East-West negotiations, I suggest that such partisan perception may further be linked to cultural variables and described as a "barbarian bias," which represents a significant variable that has not been fully discussed in the current literature. This is linked to other phenomenon, such as "accidental Occidentalism" and "biased benchmarking," which can be used, knowingly or unknowingly, by both individual and collective-based negotiators to their possible detriment.

Keywords: negotiation, barbarian bias, East-West negotiation, cross-cultural negotiation, partisan perceptions, benchmark bias

* This article is possible due to a generous research grant provided by Ewha Womans University. Associate professor and department chair at Ewha Womans University, Graduate School of International Studies, 11-1 Daehyun-dong, Seodaemun-gu, Scoul 120-750, Korea. Tel.:+82-2-3277-4077; E-mail: jaskim@ewha.ac.kr 
Negotiation: n. 1. A consensual bargaining process in which the parties attempt to reach agreement on a disputed or potentially disputed matter.

BLACK'S LAW DiCTIONARY ${ }^{1}$

Barbarian [bär-'ber-ē-ən]: Latin barbarus, 14th century 1: adj. of or relating to a land, culture, or people alien and usually believed to be inferior to another land, culture, or people 2: $n$. lacking refinement, learning, or artistic or literary culture. Merriam-Webster Dictionary ${ }^{2}$

\section{I . INTRODUCTION}

$\mathrm{T}$ he term "barbarian" has historically been used by almost every major region in the world against other regions in vicious game of the "insiders" versus the "outsiders." For instance, the Romans used the term "barbarian" to those not belonging to the Roman Empire, including Goths and Huns. The Iliad, is thought to have used the term "barbarophono" (a derivation of "barbarian") to refer to foreigners and those who spoke any language other than Greek, or those who spoke Greek poorly, ${ }^{3}$ while the Persians saw all non-Persian cultures as being "barbaric," such as the Greeks, Romans, and Arabs. Asia is also not immune to feelings of cultural superiority over others. The Han Chinese viewed other non-Chinese cultures as being foreign and thus inferior, such as the Tatars, Turks, Mongols, Manchu, Koreans, and Japanese. Moreover, the Japanese referred to Europeans visiting their island-nation, such as the Portuguese, as being barbarians (nanban).

Thus, many major cultures, including individuals and various organizations from such cultures, from "East" to "West," have at some point in its history taken a "holier than thou" approach to people, societies, and methodologies unlike their own, no matter how historically rich or advanced the culture, country, and history. Moreover, harboring this sense of bias has been used by both sides of the negotiating world-the West with the East, as well as the East with the West.

In Fisher and Ury's (1991) seminal text, Getting to Yes, the term "partisan perceptions" was used to describe such gaps in subjective understanding, noting that "conflict lies not in objective reality, but in people's heads $\cdots$ it is ultimately the reality as each side sees it that constitutes the problem in a negotiation and opens the way to a solution," positing one solution for this of "put[ting] yourself in their shoes," (22-23). This has proved to work extremely well within many areas of intercultural negotiations, especially those from similar cultures, such as negotiations between parties from North America, Western Europe, Israel, and Australia/New Zealand, to name just a few. However, when East 
and West meet at a negotiation table, a more narrowly-tailored approach may also be of benefit.

In such cases involving East meets West, often but not always, a lack of understanding regarding the counterparty's "alien" culture may prevent such a Getting to Yes-based solution from reaching its full potential. Further, the very perception of viewing the counterparty as "alien" may also trigger other partisan perceptions, such as "inferiority" and "lack of refinement." As the notion above suggests, this brings about what I refer to as a "barbarian bias"-defined as a partisan perception subset whereby one negotiation party perceives themselves to be, for whatever reason, correctly or incorrectly, somehow superior in terms of negotiation culture relative to the other negotiation side-within East-West negotiations that often acts to stymie rather than spur negotiated agreements.

This proposed barbarian bias theory is distinguishable from other general works that link culture and conflict resolution (Avruch 1998), or more specific cross-cultural research theories, such as the "four-factor model of persuasion" and "culturally-normative strategies" within cross-cultural negotiations (Adair, Brett, Okumura, and Taylor 2007), "politeness theory," (Friedman, Olekalns and Oh 2007), "power of ethics," (Young 2008), and research relating to creative conflict management through "playfulness, humor, and "punch lines" (Sclavi 2008) in that this article discusses and analyzes the dynamics behind the "barbarian bias" within cross-cultural negotiations. At the same time, more general negotiation theories such as Richard Shell and Dixit \& Nalebuff relate to factors not directly related to cross-cultural, East-West negotiations. However, all such theories are related in terms of devising creative theoretical solutions for complex negotiations in which a gap in understanding may exist between diverse parties.

I suggest here that, within the context of a cross-cultural East-West bargaining process, albeit integrative or distributive in nature, if a negotiating party harbors such a notion (implicitly or explicitly, knowingly or unknowingly) -that the negotiator sitting on the other side is a barbarian -then the potential increases somewhat notably for a failed agreement between the parties. This is mainly because the negotiation process should be by definition a "consensual" one, and that if one side senses or even begins to sense the feeling of being treated as an inferior, then whatever bridge of consensual interaction has been built will at the very least be severely stress-tested, especially in our increasingly globalized world. Such negative negotiation outcome becomes even more likely if both sides view the other as a barbarian who, by the above definition, is seen as "alien" and thus "inferior" to their own.

Such sentiment can occur due to such things as one party's inability to master a language 4 (for example, the English language), perceived differences in the sophistication and reputation, and outward appearances, 5 which makes for a challenge in terms of reaching, as Wong (2006) would argue, "a true meeting of the minds across legal systems and cultures" (439). 
Even today in the $21^{\text {st }}$ century, such proclivities still exist. Behind the most novice and most sophisticated negotiators are people with their own partisan perceptions. Naturally, experience and training help to mitigate such partisan perceptions, but probably does not mitigate such factors completely. Thus, the issue is not whether such partisan perceptions exist or not, but rather, what is the most effective approach to mitigate such barbarian bias? Differences in languages and culture clearly increase the potential for greater conflict at the negotiation table. As noted by Fisher and Ury (1991), "[w]here the parties speak different languages the chance for misinterpretation is compounded," observing that "in Persian, the word "compromise'6 apparently lacks the positive meaning it has in English" (33). Roger Fisher (joining another Harvard Negotiation Project colleague, Scott Brown) persuasively argued that the "more foreign the other side in a relationship, the less likely we are to know what is important to them. Where there are differences of language, custom, and culture, it requires imagination and effort to identify potential problems" (Fisher and Brown 1989, 67).

\section{EYES WIDE SHUT: PARTISAN PERCEPTIONS}

Fisher and Ury (1991) argue that many partisan perceptions are derived from fear, suggesting as a solution to not "deduce their intentions from your fears" (Fisher and Ury 1991, 25). But apart from such fear factor, the barbarian bias can also be a result of cultural negligence, or even worse, recklessness. Negligence can occur in the form of failing to demonstrate a sufficient level of cultural curiosity or not possessing adequate cultural knowledge about the other party (whereby culture can exist at the corporate or societal level). Recklessness can occur when, irrespective of such awareness of such cultural sensitivities and differences, one makes counterproductive statements or takes certain actions that stymies rather than furthers the deal.

Folberg et al. (2005) states that "[o]ur individual perceptions determine how we view ourselves, others, and the world" (27). He goes on to state that in the classic Japanese film, Rashomon, "one person's eyes may be very different from another's, as seen through the prism of their own perceptions," whereby the story-telling of the death of a Samurai warrior, various characters tell the "truth," which is perceived differently by different parties (28). In the Conflict Helix, R.J. Rummel refers to the "subjectivity principle" whereby "[p]erceived reality is your painting," "[l]earning a language is part of learning to perceive the world," and "[c]ultures are systems of meanings laid onto reality" (Folberg 2005, 28-29, quoting Rummel (1991)). Thus, according to Rummel's theory, if one perceives politicians and bankers as corrupt or greedy, one will be more inclined to see their shortcomings, and thus have less patience for seeing things from their counterparty's perspective. 
Because a negotiation is by definition a "consensual bargaining process.. [between] parties," when one combines a negotiation process with the notion, however rational or irrational, that such negotiations may be occurring with or against "barbarians," then the process is destined to fail more than succeed from its very inception. This represents a potentially significant deadweight cost to the related parties involved in addition to possibly impeding a good faith negotiation process that attempts to create value by mitigating partisan perceptions (Mnookin 2004; Shell 2006).

\section{SOCRATES V. CONFUCIUS: WHAT A DIFFERENCE A CULTURE MAKES ${ }^{7}$}

Many negotiators from the West were raised in an individual-based environment, which is relatively "flat" 8 compared to many collective-based "vertical" social structures. Strange from the perspective of many Confucian, collective-based societies, many parents from individual-based groups will indirectly, and often unknowingly, begin the informal negotiation training from a very early age. This reflects the Socratic approach to teaching, which is much more prevalent in individual-based societies than collective-based societies, and is reinforced by a barrage of assignments, which tests the ability to question, such as the requirement to write critical essays. Such tasks require the person (and future negotiator) to think independently, question assumptions, and then come to a personal conclusion based on the evidence. In other words, a person in this type of Socratic-based "flat" environment reinforces the use of rationality over emotion.

Yang's study relating to cross-cultural processes dealing with negotiations in Asia who tend to distinguish further between "ingroups" and "outgroups" relative to their Western counterparts is relevant in this context. Yang's study suggested that negotiators from high context cultures, such as Hong Kong, applied more zero-sum game distributive (rather than positive-sum game integrative) approaches, which led to lower pareto efficiency and less joint satisfaction (Yang 2008). This could very well relate to the notion that non-Socratic based teaching influences in Northeast Asia can play a notable role in negotiations where one is taught from an early age to conform by thinking more "in the box" than "out of the box."

In the professional work setting, the individual-based future negotiator enters a structure that is also relatively flat and horizontal. Although some hierarchy and reporting lines exist on paper, in effect, each employee is expected to be proactive, which includes the acceptance of suggestions to question and improve existing structures and methods. When an individual-based negotiator is given a task by another team member, asking "why" is not a bad thing. In fact, not asking "why" may be viewed as inappropriate inaction. In other words, 
from the outset, Socratic-based negotiators see most (but not all) things as potentially negotiable, in stark contrast to collective-based negotiators.

However, in many collective-based negotiation settings, this rationale approach is at times seen as a cold, calculating and detached process, counter to their basic instincts and training. In stark contrast, the typical collective-based individual is raised by parents typically (but not always) set in a strict vertically based structure, in which dominant parent figures effectively lay down the "law of the land" in the household. The collective-based future negotiator, as a young person, is usually told, not asked, what to do. 9 This goes from small things like what to eat, to bigger-ticket items like what to study, who to date, and when to go home.

On a similar note, Sebenius and Qian of the Harvard Business School note in their studies how many Western parties find Chinese negotiators to be "inefficient, indirect and even dishonest," while Chinese negotiators often viewed their Western counterparts to be "aggressive, impersonal, and insincere." Sebenius and Qian argue that a better understanding of Chinese cultures upon which such mentality and manners are based are needed (Sebenius and Qian 2008, 1).

The collective-based Confucius friendship structure is primarily also a top-down, command-and-control structure based on those with seniority (sunbae in Korean, senpai in Japanese) and those who are junior (bubae in Korean, kobai in Japanese). The only rare exception to the general rule is with the small band of friends in the same class year (dong-gahp in Korean). Thus, it seems that cultural differences are quite apparent and play a large role in negotiations.

However, some argue that cultural factors, like those listed above, are overemphasized. For instance, a school of thought exists that differing negotiation styles are due more to underlying language processing frameworks in the brain, thus alluding to the fact that neuropsychological factors play an important role (McCarthy, Scheraga, and Gibson 2008). However, this school of thought represents the minority, with the main school of thought supporting the notion that culture constitutes a major factor in cross border negotiations. Mitararai of Sapporo University, for example, notes a historical example relating to the first U.S.-Japan trade negotiations prior to Commodore Perry's arrival in his research related to negotiation behavioral patterns adopted by Americans and Japanese. He also notes how the two sides viewed the term "negotiation" and its connotations differently, which link to the concept of the hierarchical vertical structure seen in Northeast Asian negotiators (Mitararai 2004).

In short, the collective-based social, academic, and working structures share one commonality-they are all vertically-based top-down operating structures. This is a very important missing factor in terms of why many collective-based groups are not instinctual negotiators. For this reason, of course, the collective-based negotiators can be effective negotiators, but can often find it unusual and awkward.

In fact, for many collective-based group negotiators, which is separate but 
related to the concept of power distance, it is usually never a factor because no one dares to use it. And when it is needed, say in a negotiation on a free trade agreement, it is new and thus viewed as an "all-or-nothing," "black-or-white," "your-win-is-my-loss" vertical proposition sometimes akin to outright warfare. This mentality exists because collective-based groups have been living in this environment for their entire lives. Much like with Persians, for collective-based Confucians, the notion of compromise (tabyeop, in Korean) is often construed as a weakness, rather than creative problem-solving, which will usually not be viewed favorably, albeit in the private or public sector. 10

\section{INDIVIDUAL V. COLLECTIVIST GROUPS: SENSE AND SENSIBILITY}

Such perception of barbarian bias is even more potentially damaging within East-West negotiations. In collectivist groups, there is a greater awareness and thus skill set development in the area of interpreting the mood of the surrounding environment. For instance, in South Korea, failure of such a skill set is seen negatively, as denoted in the expression, "neunchi kochi opsbi" (a derogatory expression for the failure to read the mood of the group or a particular setting). ${ }^{11}$

Relating to this, Hofstede's (1980) research of individual and collective-based society have a tremendous influence to this day. He defined "culture" as the collective programming of the mind, which distinguishes members of one group or category from those of others (Hofstede 1991, 5).12 "Individualism" was generally defined as the extent to which individuals viewed themselves as more important relative to the collective, that is, the degree to which a person's preference in a particular country is towards acting as an individual rather than members of a group. "Collectivism" was defined as the association and self-identity in terms of group membership, such as the family, school, or work, which thereby links to a strong differentiation between in-group and out-group members (Hofstede 1993). The collective-based groups tend to use "we" more than "I," while the individual-based groups tend to use "I" more than "we."

Further, Hofstede and Bond (1988) developed a "Chinese Value Survey" due to concerns of potential Western bias in Hofstede's 1980 survey. This led to a dimension referred to as Confucian dynamism, which included such things as status-based relationships, sense of shame, thriftiness, and persistence, which were found to have a positive correlation with positive growth. Notably, China listed Long-term Orientation (LTO) as its highest-ranking factor, South Korea listed Uncertainty Avoidance (UAI) as its highest factor, and Japan listed Masculinity (MAS) as its highest factor ${ }^{13} .^{14}$

Scholars such as Yeh and Lawrence (1995) further delineated on this point by arguing that individualism and Confucianism should not always be separated, 
and that culture should not be linked to economic growth. Liu, Friedman, and Chi (2002) also noted the influential impact of personality relating to East-West distributive (rather than integrative) negotiations, while Wong (2001) questioned the assumption of whether the Confucian collective-based societal perspectives in the home still transcend into the workplace relating to China, Hong Kong, Taiwan, and Singapore. Further, Friedman, Olekalns and Oh (2007) also test the "politeness theory" relating to negative and positive face threats for both individualistic and collectivist cultures.

\section{THE ACCIDENTAL OCCIDENTAL: POTENTIAL FOR INDIFFERENCE TO DIFFERENCES}

For the individual-based negotiator dealing with collective-based negotiators, the main related barbarian bias risk involves becoming what can be referred to as the "accidental Occidental" phenomenon. 15

The "accidental Occidentalism" phenomenon occurs when one side applies, knowing or unknowing, "biased benchmarks," usually but not always with the benchmarking of Western value systems and methods, whereby the term "global" is used almost interchangeably with the term "Western." For example, sentences like "Well, in the United States, this is how it works..." can, if used repeatedly without sufficient rationale basis, fail to persuade the collective-based negotiator because it may begin to seem more like a top-down "lecture" than a "negotiation" among equals.

Even phrases as seemingly innocent as "your country," rather than the name of the country itself, can be viewed negatively because of its potential for a "West versus the rest" connotation. In a study related to cross-cultural negotiations related to East Asian MBA students conducted by Kopelman and Rosette, such negotiators who regarded humility and deference as an important negotiation communication technique were more likely to accept an offer from a negotiator displaying "positive" rather than "negative" emotion. A follow-up study involving Hong Kong executive managers confirmed this result, whereby such Northeast Asian executives were less likely to accept an offer from Israeli executive managers who did not hold humility and deference in the same weight as an important cultural value (Kopelman and Rosette 2008).

Although many "global standards" may in fact have come from a particular country, a diverse array of methodologies and approaches can still be used as legitimate options as part of the Getting to Yes seven elements process (Fisher and Ury 1991). Often such actions are not done purposely in bad faith, but rather, accidentally without realizing the potential ramifications of such actions. Hence, the term the "accidental Occidental."

Which side-the individual or collective-based groups-holds the "correct" view 
in terms of negotiations is not at issue here. What is at issue is the potential problem of using one side's perspective as the "benchmark" value system from which the entire negotiation process is based upon. ${ }^{16}$ One side's benchmark may not necessarily be the appropriate benchmark from a counterparty negotiator who comes from a different cultural background and belief system. In a related context, Dasgupta (2008) notes in his studies how different approaches influences the processes and outcomes in negotiations, noting the various ways in which cultural aspects impacts negotiations.

For this reason, East-West negotiators must be acutely aware of "biased benchmarking"-inappropriately superimposing one's own particular cultural values and belief systems onto their counterparties. Everyone is sitting at the same table, at the same time, relating to the same potential transaction, for the same purpose (to receive some sort of benefit)-such factors should suffice to bridge the gap, if any, between the parties.

Arguably, the mere awareness of such accidental Occidentalism can help preemptively address any potential issues related to the barbarian bias.

\section{ASIAN PERSUASION: GETTING TO MAYBE}

Within East-West negotiations, individual-based groups make great efforts to be clear. Statements like "Thank you, that was very clear" or "Let me be clear, this is a firm offer" are viewed very positively from the eyes of the individual-based negotiator. From such perspective, if one is a clear communicator, then one must also be a clear thinker-one of the highest compliments for a negotiator from a Socratic and individual-based society or culture. As Barkai (2008) suggests, "effective cross-cultural negotiations" requires an understanding of Cultural Dimension Interests (CDIs), which requires specific review of cultural theories, country specific "anecdotal accounts of national negotiating behaviors," and "specific beliefs, behaviors, and practices" that impact domestic negotiation behaviors. Even Fisher and Ury's text title, Getting to Yes, implies a "yes" or "no" response to negotiations. This is natural given that Fisher and Ury are U.S.-based academics-thus influenced by the culture and perspective of their home country and culture, albeit keenly aware of the overall impact of cultural factors in the negotiation process. Although their text makes references to negotiations outside the United States, such as negotiations related to the Middle East peace process, the primary focus of the text is not based exclusively on East-West negotiations.

Specific to issues related to collective-based negotiators, the issue is not so much how to "Get to Yes," but perhaps more appropriately, how to "Get to Maybe." From the perspective of many Confucian and collective-based thinkers, being "clear" is not as highly valued as creating a "harmonious" personal and 
working environment. The idea of placing greater value on a single transaction over a personal relationship, that is, rejecting an offer on the mere basis that the offer is not more value-added at that one particular moment relative to one's BATNA (best alternative to a negotiated agreement) may often be difficult to comprehend for the collective-based negotiator, whose focus is often more on building relationships as much as "Getting to Yes" in a negotiation process. Instead of "yes" or "no," often Confucian, collective-based negotiators prefer "maybe." Instead of promising "a slam dunk," often Confucian-based negotiators prefer "best efforts" or "sincere intentions" on behalf of their counterparties. For many rooted in the individual-based mentality, the means (of a relationship) is a way of getting to the end (a deal). However, in the Confucian, collective-based mentality, it is the other way around-one often enters into a deal to get a good relationship.

\section{CONCLUSION}

The "barbarian bias," as defined and described in this article, represents a significant variable within the context of East-West negotiations that has not been fully discussed in the current literature. This is linked to other phenomenon, such as "accidental Occidentalism" and "biased benchmarking," which can be used, knowingly or unknowingly, by both individual and group-based negotiators to their possible detriment. Although the term "barbarian," has had long historical roots, and has been used by both "East" and "West," it is hoped that this article will bring about a greater awareness of such bias. With such greater awareness and knowledge, the gap between East and West can be better mitigated between the perspectives of individual and collective-based negotiators.

\section{REFERENCES}

Adair, Wendi L., Brett, Jeanne M., Okumura, Tetsushi, and Taylor, Masako. 2007.

Getting What You Want: The Role of Culture in Predicting the Effectiveness of Informational and Relational Persuasive Strategies in Conflict Resolution. IACM 2007 Meetings Paper.

Avruch, Kevin. 1998. Culture and Conflict Resolution. United States Institute of Peace Press.

Barkai, John. 2008. Cultural Dimension Interests, the Dance of Negotiation, and Weather Forecasting: A Perspective on Cross-Cultural Negotiation and Dispute Resolution. Pepperdine Dispute Resolution Law Journal 8( 3).

Collins, M.S. 2005. Transcending Dualistic Thinking in Conflict Resolution. 
Negotiation Journal 21: 263.

Dasgupta, Anjan. Cultural Dynamics in International Negotiations. University of Toronto, Faculty of Law, Working Paper.

http://papers.ssrn.com/sol3/papers.cfm?abstract-id $=651185$

Fisher, R. and Ury, W. 1991. Getting to Yes: Negotiating Agreement Witbout Giving In. New York: Penguin Books.

Fisher, R. and Brown, S. 1989. Getting Together: Building Relationships As We Negotiate. Penguin: New York: Penguin Press.

Folberg, J., Golann, W., Kloppenberg, and Stipanovich, T. 2005. Resolving Disutes: Theory, Practice, and Law. New York: Aspen Publishers.

Friedman, R.A., Olekalns, M., and Oh, S.H. 2007. Choosing Your Words Carefully: Managing 'Face' During On-Line Dispute Resolution. IACM 2007 Meetings Paper. http://papers.ssrn.com/sol3/papers.cfm?abstract-id=1111637

Garner, B.A. 2001. Legal Writing in Plain English: A Text with Exerises. Chicago: University of Chicago Press.

Hall, Edward T. 1976. Beyond Culture. Norwell, MA: Anchor Books.

Hofstede, Geert. 1991. Management in a Multicultural Society. Malaysian Management Review 25: 3-12.

Hofstede, Geert. 1980. Motivation, Leadership, and Organization: Do American Theories Apply Abroad? Organizational Dynamics 9: 42-63.

Hofstede, Geert, Bond, C.M., and Luk, C.L. 1993. Individual Percpetions of Organizational Cultures: A Methodological Treatise on Levels of Analysis. Organization Studies 40: 4-13.

Hofstede, G. and Bond, M.H. 1988. The Confucius Connection: From Cultural Roots to Economic Growth. Organizational Dynamics 16: 4-21.

Kim, Jasper. Are Koreans trained to negotiate? Korea Herald. June 29, 2008. Kopelman, Shirli and Rosette, Ashleigh Shelby. 2008. Cultural Variation in Response to Strategic Display of Emotions During Negotiations. Group Decisionand Negotiation (GDN), Special Issue on Emotion and Negotiation 17(1): 65-77.

Lee, Catherine. 2007. The New Rules of International Negotiation: Building Relationships, Earning Trust, and Creating Influence Around the World. Franklin Lakes, NJ: Career Press.

Liu, L.A., Friedman, R.A., and Chi, S.C. 2002. Negotiating in Different Cultures: Are Western Personality Dimensions Relevant in Chinese Culture? Working Paper Series for the $15^{\text {th }}$ Annual Conference of the International Association for Conflict Management.

http://papers.ssrn.com/sol3/papers.cfm?abstract-id=305202

March, M. M. 1990. The Japanese Negotiator: Subtlety and Strategy Beyond Western Logic. Tokyo: Kodansha International.

McCarthy, John F., Scheraga, Carl A., and Gibson, Donald E. Culture, Cognition and Conflict: How Neuroscience Can Help to Explain Cultural Differences 
in Negotiation and Conflict Management. IACM $21^{\text {st }}$ Annual Conference Paper. http://papers.ssrn.com/sol3/papers.cfm?abstract-id $=1298588$

Mitararai, Shoji. An Exploration of the History of Cross-cultural Negotiation: The First U.S.-Japan Trade Negotiation before Commodore Perry's Arrival. Sapporo University. http://papers.ssrn.com/sol3/papers.cfm?abstract-id $=602701$

Mnookin, R., Peppet, S., and Tulumello, A. 2004. Beyond Winning: Negotiating to Create Value in Deals and Disputes. Cambridge: Belknap Press.

Pryles, M.C. $3^{\text {rd }}$ ed. 2006. Dispute Resolution in Asia. Netherlands: Kluwer Law International.

Saccone, R. 2003. Negotiating with North Korea. Elizabeth, N.J.: Hollym International Corp.

Sclavi, M. 2008. The Role of Play and Humor in Creative Conflict Management. Negotiation Journal April: 157.

Sebenius, James K. and Qian, Cheng (Jason). Cultural Notes on Chinese Negotiating Behavior. 2008. Harvard Business School Working Paper 09-076. http://www.hbs.edu/research/pdf/09-076.pdf

Shell, R.G. $2^{\text {nd }}$ ed. 2006. Bargaining for Advantage: Negotiation Strategies for Reasonable People. New York: Penguin Press.

Yeh R.S. and Lawrence, J.J. Individualism and Confucian Dynamism: A Note on Hofstede's Cultural Root to Economic Growth. Journal of International Business Studies 26: 655-669.

Wong, E.Y. 2001. The Chinese at Work: Collectivism or Individualism? Working Paper Series for the Hong Kong Institute of Business Studies, Lingnan University. http://www.library.ln.edu.hk/etext/hkibs/hkws-0040.pdf

Wong, Eleanor. 2006. In the Space between Words and Meaning: Reflections from Translating Lao Laws to English. Singapore Journal of Legal Studies: 439. http://papers.ssrn.com/sol3/papers.cfm?abstract-id=1070981\#\#.

Wydick, R.C., $5^{\text {th }}$ ed. 2005. Plain English for Lawyers. Durham: Carolina Academic Press.

Yang, Guang. Cross-Cultural Comparison of the Processes and Outcomes of Buyer-Seller Negotiations through Instant Messaging: Hong Kong Chinese vs. Americans. School of Management, Dalian University of Technology, Department of Marketing, School of Business, The George Washington University, Working Paper.

http://papers.ssrn.com/sol3/papers.cfm?abstract-id $=1275902$

Young, M. 2008. Sharks, Saints, and Samurai: The Power of Ethics in Negotiation. Negotiation Journal April: 145.

Zakaria, F. 2008. The Post-American World. New York: W.W. Norton \& Company, Inc. 


\section{ENDNOTES}

1 See Black's IAw Dictionary 1064 (8thed., 2004).

2 See Merriam-Webster Dictionary. http://www.merriam-webster.com/dictionary/barbarian(last visited September8, 2008).

3 This included the Germans, Indians, Persians, and Egyptians, among others.

${ }^{4}$ For an interesting interdisciplinary article that incorporates linguistics and Eastern religions, see Collins' paper (2005) entitled "Transcending Dualistic Thinking in Conflict Resolution."

"As one example, Confucian-based negotiators place heavy emphasis on aesthetic appearances, based on the belief that one can distinguish between a "man and a barbarian from the clothes he wears." This is partly why packaging and form in places like Japan, China, and South Korea are critically important, while in the more Western and Socratic-based societies, the substance (over form) approach is given more consideration.

6 In contrast to the Persians, another example of a slightly different connotation behind the term "compromise" can be seen with the North Koreans, who "do not view compromise as a weakness ... [but] will not allow their compromise to appear as a weakness" (Saccone 2003: 36). In the Japanese context, the term is construed as indicating "a uniquely Japanese way of solving problems or reaching decisions through a display of goodwill, by mutual trust, and reaching mutually acceptable positions through fine adjustments of one's positions or demands $\cdots$. It also relates to the frequent Japanese search for what they have in common with others, Japanese or Westerners" (March 1990: 128; Lee 2007). It also emphasizes the role of relationship-building, also echoed by Pryles (2006) but from a more region-specific perspective focusing on Asia.

7 This section (only) is an adaptation of an op-ed piece written also by the author entitled, "Are Koreans trained to negotiate?" Korea Herald. June29, 2008.

8 I define "flat" to mean a relatively hierarchal social structure, in which factors such as age, profession, and education are viewed as relatively non-important in comparison to collective-based "vertical" social structures in which such factors are viewed as relatively important.

9 For example, if the collective-based child is told to eat everything on the dinner plate, a "no" is construed as a potential sign of betrayal against a superior.

${ }^{10}$ Relating to this, Sclavi (2008) noted her experience with a South Korean nun who was told to look straight into the eyes of an older person-an act that would be considered disrespectful from the perspective of collective-based groups like South Koreans, but conversely, may represent honesty and integrity from the perspective of individual-based groups (Sclavi 2008: 160).

"In 1976, Edward Hall's seminal text Beyond Culture introduced the notion of "high context" and "low context" cultures, whereby pursuant to such classification, many "Eastern" cultures can be viewed as "high context" due to the necessity to interpret communication based on societal and cultural context, and many "Western" cultures can be viewed as "low context" due to the relative lack of need to interpret communication based on an exact societal and cultural context (Hall 1976).

12 Hofstede's data from his ground-breaking 1980 survey was derived from employee surveys relating to IBM subsidiaries in various countries, noting that such nations differed in terms of the four areas of primary dimensions, power distance, uncertainty avoidance, individualism, and masculinity (Hofstede 1980). Among the very wealthiest surveyed nations, a negative correlation was found between individualism and economic growth (although no such correlation was found among all forty surveyed countries).

13 For clarity, MAS is defined as the "differential in distribution of roles between genders."

${ }_{15} \mathrm{See}$ http://www.geert-hofstede.com/hofstede-china.shtml

15 Although exact definitions vary, the term "Occidental" often is used interchangeably with the "West," specifically Western Europe, while the term "Oriental" refers to the "East" (of Europe). For such reasons, and because such terms may be construed negatively (as being seen as based on such biases), the use of both terms are no longer as prevalent. Historically, the 1200-1400's represented a period of immense growth for "the East," Asia, and China, as reflected in Zakaria's (2008, 50) assertion that Nanjing represented the "world's largest and most advanced shipbuilding port" in the world. This period was then followed by the European Renaissance period, and the industrial revolutions in England, and finally, the emergence of the United States as the dominant economic and military figure of the twentieth century-the totality of such world events culminated into a "comeback" for the West (individual-based groups). It is not until the last few years, when the pendulum of world economic flows have begun to shift back towards Asia and other non-Western nations, such as India and China (relatively more collective-based group), as famously noted by the Goldman Sachs report, Dreaming with BRICs: The Path to 2050. (Goldman Sachs Report 2003).

${ }^{16}$ Doing this is akin to using the term "Oriental" rather than "Asian" or "Occidental" rather than "European." For clarity, the latter terms are neutrally-based yet still convey the same general geographic information, while the former terms represent biased benchmarks towards a particular culture. 